\section{Sympathetic hyperactivity syndrome following cerebral fat embolization}

JEFFREY B JENSEN • JAMES ONIGKEIT • SARA HOCKER
JEFFREY B JENSEN ( $\square) \bullet$ JAMES ONIGKEIT

Department of Anesthesiology Divison of Critical Care Mayo Clinic 2001 st Street

Rochester, Minnesota MN 55901

Phone: 507 255-9814

E-mail: jensen.jeffrey@mayo.edu

SARA HOCKER

Department of Neurology

Division of Critical Care, Mayo Clinic

Rochester, Minnesota

\begin{abstract}
To date, there have been no reports of paroxysmal sympathetic hyperactivity syndrome (PSHS) associated with cerebral fat embolization. We describe the case of a young male who developed acute brain injury and acute hypoxemic respiratory failure secondary to significant fat embolization following a traumatic femur injury. Our patient demonstrated episodes of significant hypertension, tachycardia, fever and extensor posturing. Extensive evaluation lead to the diagnosis and appropriate treatment for PSHS. Ultimately, the patient went on to have a good neurologic recovery after a prolonged hospitalization. We will discuss PSHS diagnostic criteria, pathophysiology and treatment options. This diagnosis should be considered in all brain-injured patients with paroxysms of autonomic instability and abnormal movements.
\end{abstract}

Key words: acute brain injury, myoclonic encephalopathy, fat embolism, autonomic nervous system diseases, adult respiratory distress syndrome,wound, injuries

\section{Introduction}

We report a case of a young male with a femur fracture following a motor vehicle collision who develops cerebral fat embolization. As a consequence of his brain injury he develops a constellation of signs/symptoms consistent with Paroxysmal Sympathetic Hyperactivity Syndrome (PSHS). This clinical presentation is one of sympathetic autonomic dysfunction. Four of the 6 following criteria (tachycardia, fever, hypertension, tachypnea, diaphoresis or extensor posturing) are necessary for diagnosis. Awareness of this syndrome will lead to a timely diagnosis and appropriate therapy.

\section{Case report}

A 21 year-old male was involved in a high-speed motor vehicle collision. His past medical history was significant for methamphetamine abuse. Injuries were limited to a mid-shaft femur fracture with an open distal patellar fracture. On the evening of the injury, he underwent irrigation and debridement with antibiotic bead placement for his open fracture along with a proximal tibial traction pin for temporary stabilization. There were no immediate intraoperative complications and the patient was transferred to an orthopedic general care unit after satisfactory anesthetic recovery.

Approximately fourteen hours postoperatively, he developed sudden onset of confusion and agitation associated with chest pain, dyspnea, tachycardia, hypoxemia, and hypotension. The rapid response team was called to his bedside. He was subsequently intubated for hypoxemic respiratory failure and transferred to the intensive care unit (ICU) with the presumptive diagnosis of an embolic syndrome (fat vs. thromboembolic).
Physical examination was unremarkable except for his lower extremity injuries and scattered crackles anteriorly on lung auscultation. No petechial rash was identified. A portable chest film showed new bilateral infiltrates. An emergent chest computed tomography (CT) angiogram did not demonstrate any filling defects. Bilateral parenchymal interstitial changes consistent with edema were noted. Transthoracic echocardiogram revealed moderately reduced right ventricular (RV) function with dyssynchronous interventricular septal motion, right ventricular systolic pressure of $44 \mathrm{~mm} \mathrm{Hg}$ (systemic pressure was $108 \mathrm{~mm} \mathrm{Hg}$ ) and a dilated inferior vena cava (IVC). Left ventricular (LV) ejection fraction was reduced (48\%), but no regional wall motion abnormalities were seen. Laboratory data were unremarkable except for mild leukocytosis and anemia. The ratio of partial pressure of oxygen in arterial blood to fraction of inspired oxygen (P/F ratio) was 100. A working diagno- 
sis of acute respiratory distress syndrome (ARDS) secondary to fat emboli syndrome was made. A lung-protective ventilation strategy and other supportive measures were employed.

On ICU day 2, femur stabilization with an external fixation device and patellar tendon repair occurred without complication. A chest film demonstrated improving bilateral infiltrates with a corresponding increase in his $\mathrm{P} / \mathrm{F}$ ratio. During a sedation holiday on ICU day 3 , the patient experienced 2 episodes of extensor posturing in all extremities with eye deviation and masseter muscle rigidity. These spells appeared to have resolved with intravenous benzodiazepines and fosphenytoin loading. Head CT was negative for any acute intracranial pathology. Physical exam demonstrated new petechiae over his upper chest and axilla. Despite therapeutic phenytoin levels, the patient continued to have episodes of extensor posturing, tachycardia, tachypnea, profuse sweating and fevers on ICU day 4. Electroencephalogram (EEG) monitoring demonstrated no epileptogenic activity during these spells.

A neurology consultation was requested for these spells and the patient was subsequently diagnosed with PSHS. An

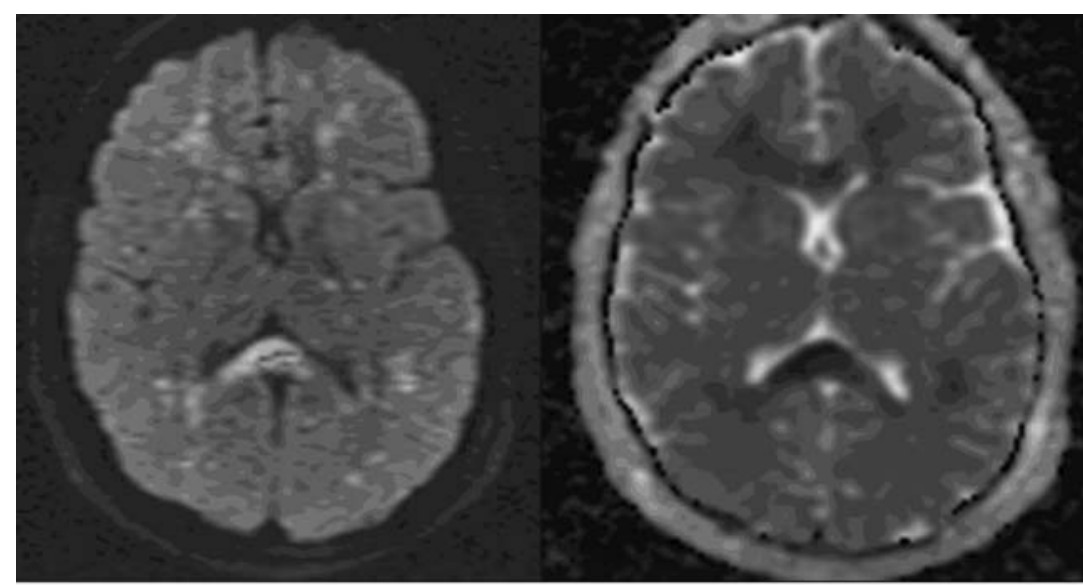

Figure 1: "Starfield" pattern seen in cerebral fat embolization characterized by innumerable foci of restricted diffusion, predominantly within the subcortical and deep white matter, but also involving the thalamus, basal ganglia and corpus callosum.

magnetic resonance imageing (MRI) was obtained and demonstrated changes consistent with cerebral fat embolism with innumerable foci of restricted diffusion within the subcortical and deep white matter involving both infra and supratentorial regions. The imaging was consistent with the "star field pattern" of cerebral fat emboli (figure 1). (1) The treatment of the PSHS included clonidine, gabapentin, morphine, propranolol and lorazepam. Ultimately, the spells decreased in frequency and duration.
On ICU day 15, he was transferred to a general neurology floor. He was obtunded, had intermittent eye opening, and did not following any commands. He had undergone tracheostomy and percutaneous gastrostomy tube placement. Prior to dismissal from the hospital, the patient became more alert and interactive. This improvement resulted in admission to brain rehabilitation program 51 days post injury. Ultimately, his spells resolved and he was weaned from all neuroleptic medications. After

Table 1. Differential diagnosis of paroxysmal sympathetic hyperactivity syndrome.

\begin{tabular}{|c|c|c|c|c|c|c|}
\hline & PSHS & Seizures & NMS & $\mathrm{MH}$ & $\begin{array}{l}\text { Serotonin } \\
\text { Syndrome }\end{array}$ & $\begin{array}{l}\text { Sympathomimetic } \\
\text { Syndrome }\end{array}$ \\
\hline History & $\begin{array}{l}\text { Acute brain } \\
\text { injury }\end{array}$ & $\begin{array}{l}\text { Acute or remote brain } \\
\text { injury, } \\
\text { epilepsy syndrome }\end{array}$ & $\begin{array}{l}\text { Neuroleptics - } \\
\text { initiation or dose } \\
\text { titration }\end{array}$ & $\begin{array}{l}\text { Volatile } \\
\text { Anesthetics \&/or } \\
\text { Succinylcholine }\end{array}$ & $\begin{array}{l}\text { SSRI, serotonin ago- } \\
\text { nists (fentanyl, trip- } \\
\text { tans), amphetamines } \\
\text { or cocaine }\end{array}$ & $\begin{array}{l}\text { Amphetamines, } \\
\text { MDMA, cocaine }\end{array}$ \\
\hline Treatment & Symptomatic & Antiepileptic agents & $\begin{array}{l}\text { Cessation of } \\
\text { neuroleptics } \\
\text { Bromocriptine }\end{array}$ & $\begin{array}{l}\text { Discontinue } \\
\text { triggering agents } \\
\text { Dantrolene }\end{array}$ & $\begin{array}{l}\text { Benzodiazepines } \\
\text { Cyproheptadine }\end{array}$ & $\begin{array}{l}\text { Symptomatic } \\
\text { support } \\
\text { Benzodiazepines } \\
\text { Haloperidol }\end{array}$ \\
\hline Clinical Signs & $\begin{array}{l}\text { Altered mental } \\
\text { status } \\
\text { Hyperthermia } \\
\text { Autonomic } \\
\text { dysfunction } \\
\text { Muscle Rigidity }\end{array}$ & $\begin{array}{l}\text { Altered mental status } \\
\text { Eye deviation } \\
\text { Autonomic } \\
\text { dysfunction } \\
\text { Muscle Rigidity }\end{array}$ & $\begin{array}{l}\text { Altered mental } \\
\text { status } \\
\text { Hyperthermia } \\
\text { Autonomic } \\
\text { dysfunction } \\
\text { Muscle Rigidity }\end{array}$ & $\begin{array}{l}\text { Altered mental } \\
\text { status } \\
\text { Hyperthermia } \\
\text { Autonomic } \\
\text { dysfunction } \\
\text { Muscle Rigidity }\end{array}$ & $\begin{array}{l}\text { Altered mental status } \\
\text { Hyperthermia } \\
\text { Autonomic dysfunc- } \\
\text { tion } \\
\text { Muscle Rigidity }\end{array}$ & $\begin{array}{l}\text { Altered mental } \\
\text { status } \\
\text { Hyperthermia } \\
\text { Autonomic } \\
\text { dysfunction } \\
\text { Muscle Rigidity }\end{array}$ \\
\hline Onset & variable & variable & 24-72 hours & $\begin{array}{l}\text { Immediate } \\
\text { to a day }\end{array}$ & 6-24 hours & $\begin{array}{l}\text { Immediate to } \\
\text { a day }\end{array}$ \\
\hline $\begin{array}{l}\text { Laboratory/ } \\
\text { Diagnostic }\end{array}$ & none & Electroencephalogram & $\begin{array}{l}\text { Elevated serum } \\
\text { creatine kinase }\end{array}$ & $\begin{array}{l}\text { Elevated serum } \\
\text { creatine kinase }\end{array}$ & none & Tox Screen \\
\hline
\end{tabular}

NMS, Neuroleptic Malignant Syndrome; MH, Malignant Hyperthermia; MDMA, 3,4-methylenedioxy-Nmethylamphetamine/“Ecstasy"; PSH, Paroxysmal sympathetic hyperactivity syndrome; SRI, Serotonin Reuptake inhibtors. 
completion of his in-patient rehabilitation the patient was dismissed to his parents' home ninety-three days post initial injury.

One year following injury, the patient continues to live at home and is working at the family business. He is independent in all Activites of Daily Living (ADL's), but continues to have issues with mild cognitive impairment and impulse control.

Discussion

In this case, fat embolization in the setting of a long bone fracture resulted in a significant global central nervous system insult. This insult caused a constellation of signs and symptoms known as PSHS not previously described in the setting of cerebral fat embolization.

Fat embolism syndrome is a well-described event often associated with long bone injuries or surgical techniques requiring bone marrow space pressurization. It is characterized by a classic triad of findings including hypoxia, mental status alteration (confusion to coma) and a petechial rash. The first two criteria are nonspecific, and the third is often considered pathognomic for fat emboli despite it being present only $\sim 20 \%$ of the time.

Paroxysmal sympathetic hyperactivity syndrome was first described over 80 years ago as diencephalic autonomic epilepsy. (2) However, a comprehensive review references thirty-one different terms used to describe this phenomenon. (3) Rabinstein and colleagues proposed criteria and nomenclature that describes this constellation of signs and symptoms as paroxysmal sympathetic hyperactivity syndrome in an attempt to standardize diagnosis and nomenclature. Accordingly, a diagnosis is achieved if 4 of the 6 following criteria are met: tachycardia, fever, hypertension, tachypnea, diaphoresis or extensor posturing. (4) To our knowledge, this is the first case to describe PSHS as a consequence of cerebral fat emboli. There have been multiple descriptions of PSHS as a result of traumatic brain injury, anoxic brain injury, $(3,5,6)$ intracranial tumors, (2,7-9) and hemorrhage. $(10,11)$

Pathophysiology

The underlying pathophysiology of PSHS is poorly understood but it is felt to represent dysregulation of the autonomic nervous system. Initially it was believed to be a result of seizures occurring within the diencephalon, however, there has been no EEG evidence to support that belief in patients exhibiting PSHS. $(7,8,10,12)$ Case reports involving PSHS utilizing anti-convulsant therapy were unsuccessful at controlling these spells. $(7,12)$ Certainly seizure activity may cause a similar clinical picture, and Metz et al. were able to treat a patient with an ictal EEG correlate successfully with anti-convulsant therapy. (13) Rather than attribute the paroxysm to seizure activity, Bullard was the first to propose a disconnection type theory in which loss of control from higher cortical and subcortical centers leads to the dysregulated autonomics. (12) Baugely et al. refer to conventional disconnection theories suggesting that one or more separate sympathoexcitatory centers in the hypothalamus and brainstem actively drive paroxysms once "released" from higher control. (13) Implicated sites of damage have ranged from diencephalon to brainstem and include regions such as the periventricular hypothalamic nucleus, lateral periaqueductal gray substance, lateral parabrachial nucleus, or rostral ventral medulla among others. $(6,10,12)$ More recently Baugely has proposed that these centers themselves are inhibitory. Thus, damage to these structures results in uncontrolled excitatory spinal cord processes and proposes an excitatory: inhibitory ratio model to explain observations in patients with PSHS following head trauma and with similar central nervous system conditions. (13) Regardless of the precise mechanism, there is a net increase in sympathetic activity with a measurable increase in serum catecholamine levels during paroxysms. (11) However, measuring serum catecholamine levels is not essential to diagnose PSHS.

Treatment

Treatment is supportive and focused on symptomatic relief during catecholamine surges. Multiple medications have been used successfully in the treatment of PSHS. While no single medication has universally been successful, opioids (morphine) and beta blockers (propranolol) seem to be the most efficacious. Other medications cited in the literature include: bromocriptine, benzodiazepines, clonidine, dantrolene, intrathecal baclofen and more recently gabapentin and dexmedetomidine.

Differential Diagnosis

PSHS has clinical features similar to other syndromes that can make diagnosis difficult. Awareness of the subtle differences of these diagnoses will lead to timely and appropriate therapy. Table 1 outlines conditions which can mimic PSHS.

\section{Conclusion}

Paroxysmal sympathetic hyperactivity syndrome presents unique challenges to physicians treating brain-injured patients. Unpredictable autonomic discharges can lead to large swings in hemodynamics and abnormal movements. It is important for all physicians caring for brain-injured patients to be aware of PSHS and to familiarize themselves with treatment regimens; as inappropriate diagnosis may lead to unecessary ineffective interventions and therapies. 


\section{REFERENCES}

1. Takahashi M, Suzuki R, Osakabe Y, Asai J, Miyo T, Nagashima G, et al. Magnetic resonance imaging findings in cerebral fat embolism: correlation with clinical manifestations. J Trauma 1999;46(2):324-7.

2. Penfield W. Diencephalic Autonomic Epilepsy. Arch Neurol Psychiatry 1929;22:2.

3. Perkes I, Baguley IJ, Nott MT, Menon DK. A review of paroxysmal sympathetic hyperactivity after acquired brain injury. Ann Neurol 2010;68(2):126-35.

4. Rabinstein AA. Paroxysmal sympathetic hyperactivity in the neurological intensive care unit. Neurol Res 2007;29(7):680-2.

5. Blackman JA, Patrick PD, Buck ML, Rust RS. Paroxysmal autonomic instability with dystonia after brain injury. Arch Neurol 2004;61 (3):321-8.

6. Diesing TS, Wijdicks EF. Arc de cercle and dysautonomia from anoxic injury. Mov Disord 2006;21(6):868-9.

7. Solomon GE. Diencephalic autonomic epilepsy caused by a neoplasm. J Pediatr 1973;83(2):277-80.

8. Goh KY, Conway EJ, DaRosso RC, Muszynski CA, Epstein FJ. Sympathetic storms in a child with a midbrain glioma: a variant of diencephalic seizures. Pediatr Neurol 1999;21(4):742-4.

9. McLean A. Autonomic epilepsy: report of a case with observation at necropsy. Arch Neurol Psychiatry 1934;1934(32):189-97.

10. Boeve BF, Wijdicks EF, Benarroch EE, Schmidt KD. Paroxysmal sympathetic storms ("diencephalic seizures") after severe diffuse axonal head injury. Mayo Clin Proc 1998;73(2):148-52.

11. Wang VY, Manley G. Recognition of paroxysmal autonomic instability with dystonia (PAID) in a patient with traumatic brain injury. J Trauma 2008;64(2):500-2.

12. Bullard DE. Diencephalic seizures: responsiveness to bromocriptine and morphine. Ann Neurol 1987;21(6):609-11.

13. Baguley IJ. The excitatory:inhibitory ratio model (EIR model): An integrative explanation of acute autonomic overactivity syndromes. Med Hypotheses 2008;70(1):26-35. 